\title{
Continuous monitoring of the health status of cement-based structures: electrical impedance measurements and remote monitoring solutions
}

\author{
Nicola Giulietti ${ }^{1}$, Paolo Chiariotti ${ }^{2}$, Gloria Cosoli ${ }^{1}$, Giovanni Giacometti ${ }^{1}$, Luca Violini ${ }^{1}$, \\ Alessandra Mobili ${ }^{3}$, Giuseppe Pandarese ${ }^{1}$, Francesca Tittarelli ${ }^{3,4}$, Gian Marco Revel $^{1}$ \\ ${ }^{1}$ Department of Engineering and Mathematical Sciences (DIISM), v. Brecce Bianche, 60131, Ancona, Italy \\ 2 Department of Mechanical Engineering, v. La Masa 1, 20156, Milano, Italy \\ ${ }^{3}$ Department of Materials, Environmental Sciences and Urban Planning (SIMAU), v. Brecce Bianche, INSTM Research Unit, 60131, Ancona, Italy \\ ${ }^{4}$ Institute of Atmospheric Sciences and Climate, National Research Council (ISAC-CNR), v. Piero Gobetti 101, 40129 Bologna, Italy
}

\section{ABSTRACT}

The continuous monitoring of cement-based structures and infrastructures is fundamental to optimize their service life and reduce maintenance costs. In the framework of the EnDurCrete project (GA no. 760639), a remote monitoring system based on electrical impedance measurements was developed. Electrical impedance is measured according to the Wenner's method, using 4-electrode arrays embedded in concrete during casting, selecting alternating current as excitation, to avoid the polarization of both electrode/material interface and of material itself. With this measurement, it is possible to promptly identify events related to contaminants ingress or damages (e.g. cracks formation). Conductive additions are included in some elements to enhance signal-tonoise ratio, as well as the self-sensing properties of concrete. Specifically, a distributed sensor network was implemented; consisting of measurement nodes installed in the elements to be monitored, then connected to a central hub (RS-232 protocol). Nodes are realized with an embedded unit for electrical impedance measurements (EVAL-AD5940BIOZ board with AD5940 chip, by Analog Device) and a digital thermometer (DS18B20 by Maxim Integrated), enclosed in cabinets filled with an IP68 gel against moist-related problems. Data are available on a Cloud through Wi-Fi network or LTE modem, hence can be accessed remotely via a use-friendly multi-platform interface.

\section{Section: RESEARCH PAPER}

Keywords: Concrete health monitoring; electrical impedance; remote monitoring; distributed sensor network

Citation: Nicola Giulietti, Paolo Chiariotti, Gloria Cosoli, Giovanni Giacometti, Luca Violini, Alessandra Mobili, Giuseppe Pandarese, Francesca Tittarelli, Gian Marco Revel, Continuous monitoring of the health status of cement-based structures: electrical impedance measurements and remote monitoring solutions, Acta IMEKO, vol. 10, no. 4, article 22, December 2021, identifier: IMEKO-ACTA-10 (2021)-04-22

Section Editor: Roberto Montanini, Università di Messina and Alfredo Cigada, Politecnico di Milano, Italy

Received July 26, 2021; In final form December 5, 2021; Published December 2021

Copyright: This is an open-access article distributed under the terms of the Creative Commons Attribution 3.0 License, which permits unrestricted use, distribution, and reproduction in any medium, provided the original author and source are credited.

Funding: EnDurCrete (New Environmental friendly and Durable conCrete, integrating industrial by-products and hybrid systems, for civil, industrial, and offshore applications) project, funded by the European Union's Horizon 2020 research and innovation programme under grant agreement $\mathrm{n}^{\circ} 760639$.

Corresponding author: Gloria Cosoli, e-mail: g.cosoli@staff.univpm.it

\section{INTRODUCTION}

With a view of optimizing the costs related to maintenance operations necessary to guarantee a service life as long and efficient as possible for cement-based structures, Structural Health Monitoring (SHM) is paramount [1]. In fact, inspections alone are not sufficient to carry out timely actions intended to cope with possible damages. Monitoring remotely structures and infrastructures is undoubtedly advantageous, since this process provides continuous data, often available in real-time, allowing to promptly act in a proactive way to avoid the risk of damages in the target structure. Solutions involving IoT-based approaches [2] have been also recently proposed, also in the context of smart cities applications [3]. These approaches demonstrated to be very promising given their distributed nature and connectivity characteristics making them prone to cloud analyses [4]. Indeed, it is possible to monitor the factors threatening the durability of a structure, intended as "the ability of concrete to resist 
weathering action, chemical attack, and abrasion while maintaining its desired engineering properties" (American Concrete Institute, ACI [5]). Particular aggressive exposure conditions (e.g. marine environments) and contaminants (e.g. chlorides and sulphates) undermine the structures durability [6], requiring interventions getting more expensive the longer the time since the damage has occurred ("The law of fives" by De Sitter states that the repairing costs increase exponentially after the structure damaging [7]). These events modify the concrete element composition and morphology, resulting in changes detectable through different techniques, such as ultrasound [8] [9], computer vision [10], [11], thermography [12], [13], ground penetrating radar (GPR) [14], [15], electrical resistivity [16], only to name a few.

The use of electrical resistivity/impedance (cell constant scaling/no scaling) measurements for SHM have grown widely [17] and achieved particular success with the introduction of conductive fillers (e.g. char, carbon black, graphene nanoplatelets, nickel powder, graphite powder, iron oxide, titanium dioxide, etc.) and fibres (e.g. virgin and recycled carbon fibres, steel fibres, carbon nanotubes, etc.) to enhance the selfsensing ability of concrete. The resulting lower electrical resistivity of the material allows to obtain a higher Signal-toNoise ratio (SNR), as well as to use low-cost instrumentation providing levels of accuracy comparable to those levels characterizing laboratory equipment. Consequently, the possibility to exploit more affordable electronic equipment paves the way to the development of distributed sensor networks to monitor cement-based structures in those areas most subjected to stress, penetration of contaminants and hence damages and degradation. Indeed, the electrical resistivity/impedance measurement is a local measurement, with a "sensing volume" corresponding to the hemisphere with the radius equal to the inter-electrode distance. Sensors positioning hence becomes of uttermost importance to get significant data.

Furthermore, this type of measurement is particularly attractive since allows to monitor a plethora of aspects: the ingress of contaminants [18], [19] (being electrical resistivity linked to the material ability to transport ions, responsible of many degradation processes [20]), the penetration of water (particularly relevant since it carries ions and also aggressive substances, such as chlorides and sulphates), changes in temperature and moisture content, the presence of stress, the formation of cracks, the corrosion of reinforcements, etc. Therefore, electrical resistivity/impedance can be assumed as an essential parameter for monitoring the health status of cementbased structures.

To perform electrical impedance measurements, a proper excitation signal should be applied to the material; this can be done by means of an electric current/potential, then measuring the corresponding electric potential/current and finally computing the resultant electrical impedance. Electrodes are necessary to carry out the measurement; different materials and configurations are reported in literature and both direct or alternating current (DC and AC, respectively) can be used, but the consequent measurement results will be different [6]. Indeed, there are no widely accepted standards for this measurement in concrete, even if recommendations are available [21], [22]. In particular, in order to avoid both material and electrode/material interface polarization (the first caused by DC, the second caused by the use of the same two electrodes for both excitation and measurement - giving the so-called "insertion error"), the Wenner's method [23] should be adopted, using four electrodes (two for the material excitation, the other two for the measurement) and $\mathrm{AC}$ with a frequency greater than $1 \mathrm{kHz}$ [21][24].

In order to remotely monitor all these aspects in a continuous way, a dedicated monitoring system was developed within the EnDurCrete project (GA no. 760639); in particular, both electrical impedance and temperature of concrete elements are measured. The developed system was tested in a Spanish demo site, as it will be described in detail below.

The paper is organised as follows: the architecture of the remote measurement system developed to monitor the health status of cement-based structures is presented in Section 2, results of laboratory tests for the monitoring system development and preliminary results of long-term monitoring activities are reported in Section 3, whereas in Section 4 the authors provide their comments and conclude the work.

\section{MATERIALS AND METHODS}

\subsection{Single node design}

Gold-standard measurement systems to perform electrical impedance measurements are galvanostats/potentiostats; their costs make their in-field use unfeasible, thus alternative sensors should be sought. Moreover, given the "local" nature of the measurement, several sensing nodes should be considered to cover those areas prone to damages. The sensing nodes developed go in this direction by exploiting an embedded unit (EVAL-AD5940BIOZ board by Analog Device) controlling the AD5940 chip for electrical impedance measurements (a similar chip, the AD5933, has been already proved to be accurate for damages detection through electrical impedance measurements [25]). The unit was set to carry out electrical impedance measurements according to Electrochemical Impedance Spectroscopy (EIS) method in galvanostatic configuration, using AC to excite the material (frequency range: $1 \mathrm{kHz}-20 \mathrm{kHz}$; resolution: $1 \mathrm{kHz}$; a signal amplitude of $600 \mathrm{mV}_{\mathrm{pp}}$ is used, limiting the flowing electric current through a current limiting resistor to comply to IEC 60601 standard - given that the employed acquisition board was originally thought for measurements on the human body). Moreover, a digital thermometer was included to monitor the concrete element internal temperature, specifically the DS18B20 by Maxim Integrated (temperature range: from $-55^{\circ} \mathrm{C}$ to $+125^{\circ} \mathrm{C}$; accuracy: $\pm 0.5^{\circ} \mathrm{C}$ from $-10^{\circ} \mathrm{C}$ to $+85^{\circ} \mathrm{C}$; 1 -wire bus communication), with stainless steel housing. The electronic board was placed inside an IP66 certified electrical box further filled with a self-sealing polymer-type insulating gel with cold cross-linking targeted to guarantee IP68 performance.

The metrological performance of the sensing nodes targeted to the EIS measurements was tested at laboratory level by comparison with a potentiostat/galvanostat used in galvanostatic configuration (Gamry Reference 600 by Gamry Instruments, considered as the gold-standard instrument). In particular, the comparison was made in terms of the real part of electrical impedance, mainly for two reasons: (i) it is directly related to electrical resistivity, in case of a pure resistive behaviour, according to the second Ohm's law; (ii) it depends on several parameters of interest (e.g. moisture content and water penetration [26], chlorides penetration [18], [27], porosity [28], carbonation depth, cracks formation [29], curing state [30]), given that it is linked to the ionic movement in the material and to the durability itself [6], [31]. 

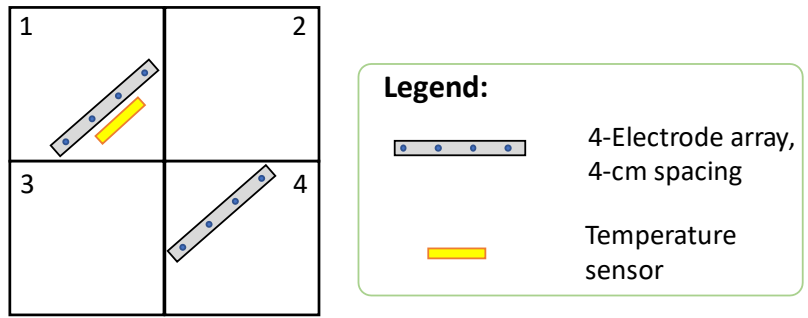

Figure 1. First concrete panel prototype: configuration scheme.
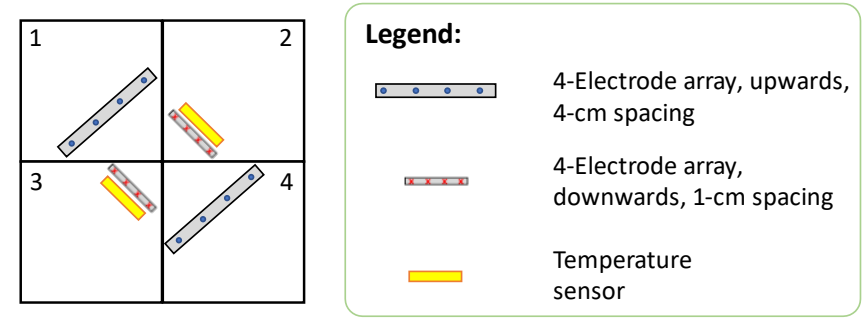

Figure 2. Second concrete panel prototype: configuration scheme.

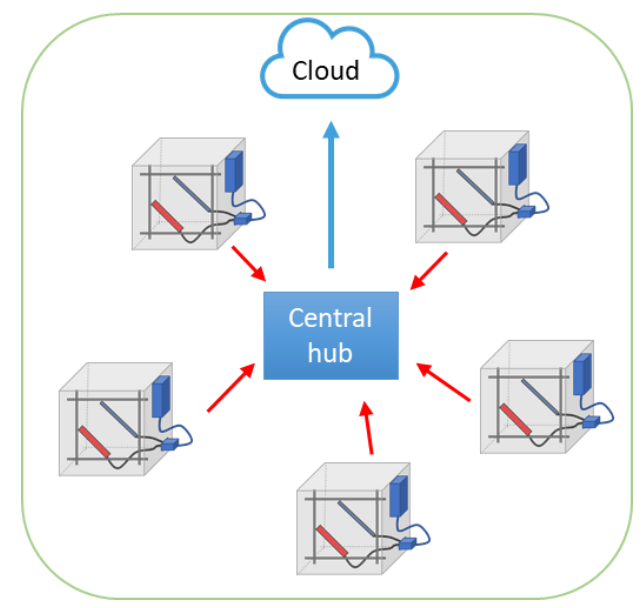

Figure 3. Monitoring system with star-network architecture, with edge devices connected to the central hub, collecting data and sending them to a Cloud that can be accessed remotely.
Laboratory acquisitions were performed on a concrete block $\left(35 \times 35 \times 20 \mathrm{~cm}^{3}\right)$ specifically manufactured for this testing activity, using the same mix-design adopted for the in-field validation phase. The concrete mix design was as follows: $375 \mathrm{~kg} / \mathrm{m}^{3}$ of cement, $908 \mathrm{~kg} / \mathrm{m}^{3}$ of calcareous sand $0 \mathrm{~mm}-$ $4 \mathrm{~mm}, 362 \mathrm{~kg} / \mathrm{m}^{3}$ of intermediate gravel $5 \mathrm{~mm}-10 \mathrm{~mm}$, $618 \mathrm{~kg} / \mathrm{m}^{3}$ of coarse gravel $10 \mathrm{~mm}-15 \mathrm{~mm}, 169 \mathrm{~kg} / \mathrm{m}^{3}$ of water, $0.55 \mathrm{~kg} / \mathrm{m}^{3}$ and $1.27 \mathrm{~kg} / \mathrm{m}^{3}$ of PC2 and PC3 superplasticizers, respectively. The concrete block was manufactured embedding both a temperature sensor and two 4electrode arrays (for performance comparison) for electrical impedance measurement (Figure 1). Stainless-steel was used for manufacturing the electrodes. Furthermore, another $35 \times 35 \times$ $20 \mathrm{~cm}^{3}$ concrete specimen was manufactured hosting two couples of electrode arrays with different spacing, namely $1 \mathrm{~cm}$ and $4 \mathrm{~cm}$, fixed at a depth of $5 \mathrm{~cm}$ and directed downwards and upwards, respectively (Figure 2); a temperature sensor was also embedded in the specimen. The results of these laboratory tests allowed to fine-tune the setting parameters of the monitoring system, as well as to better understand the factors influencing the results (e.g. panels positioning). It is worthy to underline the fact that the tests were performed at $20 \pm 1{ }^{\circ} \mathrm{C}$ ambient temperature and $50 \pm 5 \%$ relative humidity.

\subsection{Monitoring system design}

Given the targeted distributed nature of the monitoring system, a star-network architecture was selected. Each measurement node is connected to a central gateway acting as data collector (Figure 3). Serial communication (RS232) was used as communication protocol.

The central gateway also hosts a 16 channel USB to DB9 RS232 Serial Adapter Hub, an Intel ${ }^{\circledR}$ NUC mini-PC and an LTE industrial router.

A Python-based back-end service installed on the NUC sends a serial request to each node every hour and then receives the acquired data. The gateway stores data both locally in SQLite database and on cloud (AWS Amazon EC2 server) exploiting PostrgreSQL engine.

Data can be accessed remotely through a dedicated multiplatform application developed in Dart language exploiting the Google Flutter Network for Android, iOS, Linux and Windows

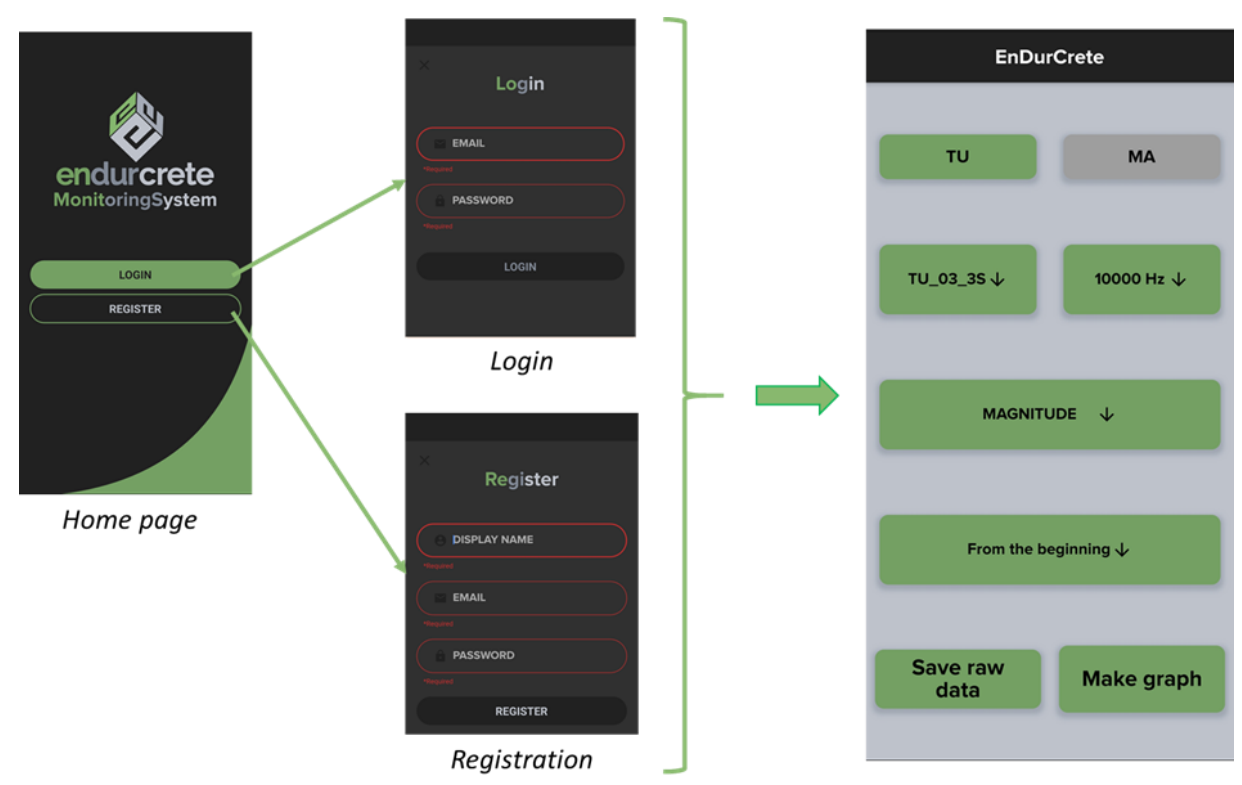

Figure 4. Mobile application for monitoring: home page (left), login and registration (centre, top and bottom) and main page (right). 


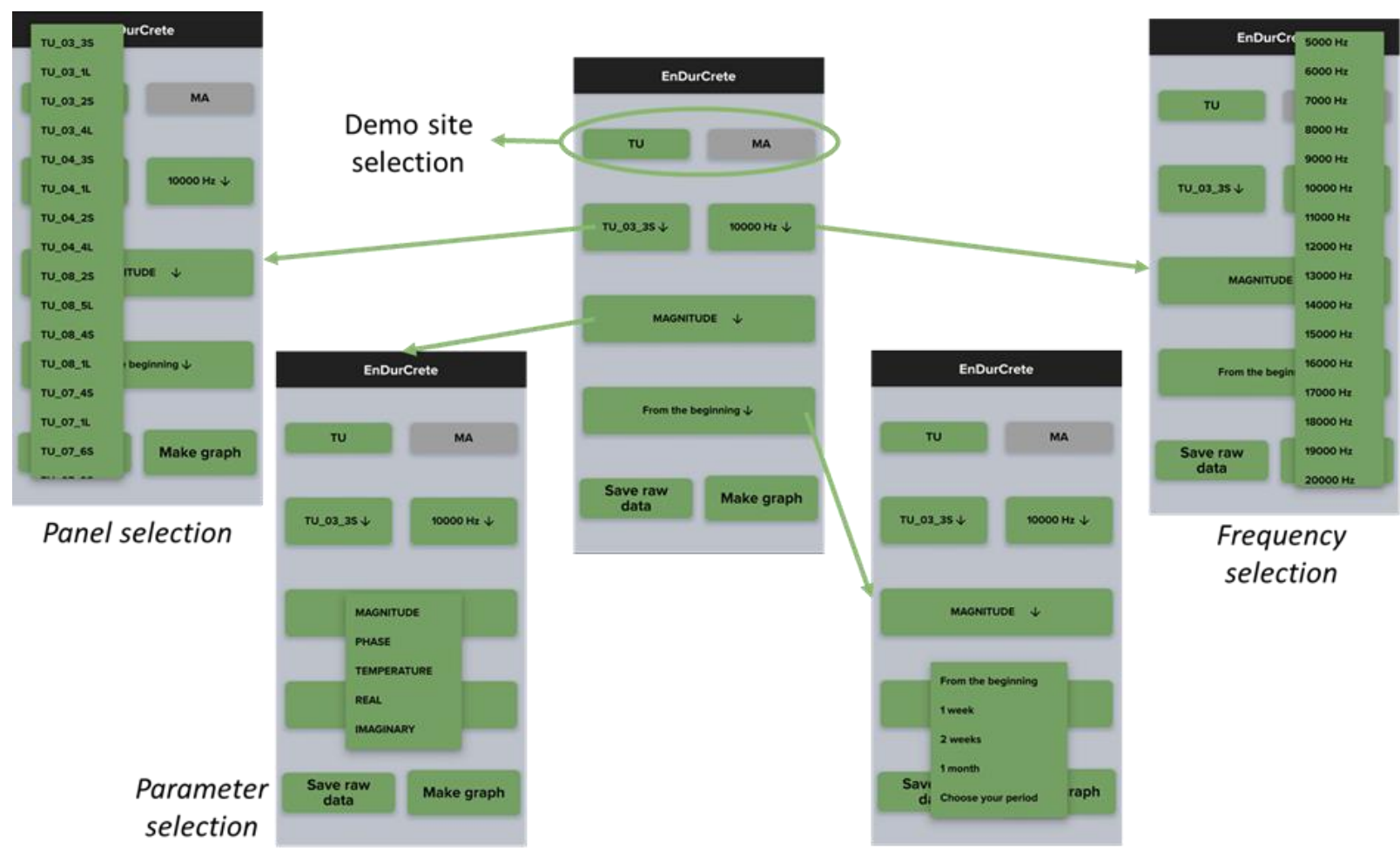

Figure 5. Mobile application for monitoring: selection of demo site, panel and electrode array, measurement frequency and parameters of interest.

environments, developed within the EnDurCrete project. As example, the application that runs on an Android device is shown in the following. At the first access, registration is required with an email address and password; after the login, it is possible to access the main page with different options (Figure 4).

It is possible to switch between different demo sites (Tunnel, TU, and Marine, MA - the second has been activated in Italy more recently and will be the object of future analyses), then select the panel and the electrode array of interest (for example the label TU_03_3S stands for tunnel demo site, panel n. 3, sensor n. 3 short (1-cm spacing) whereas the label TU_03_1L stands for tunnel demo site, panel n. 3, sensor n. 1 long (4-cm spacing)). Furthermore, it is possible to choose the measurement frequency for the electrical impedance measurement and select the desired parameters: temperature, magnitude, phase, real and imaginary parts of electrical impedance; finally, it is possible to
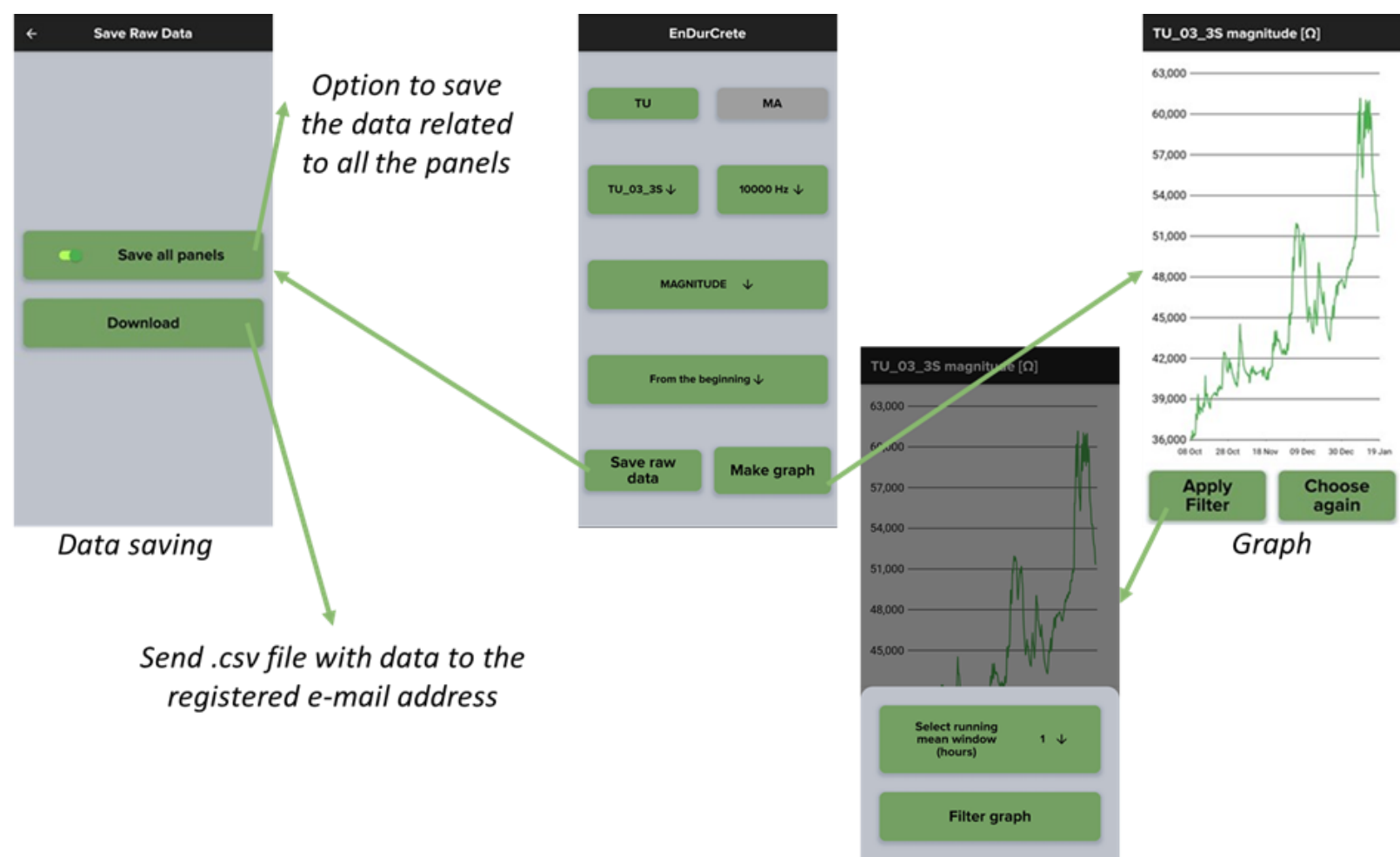

Figure 6. Mobile application for monitoring: data saving and graph making. 


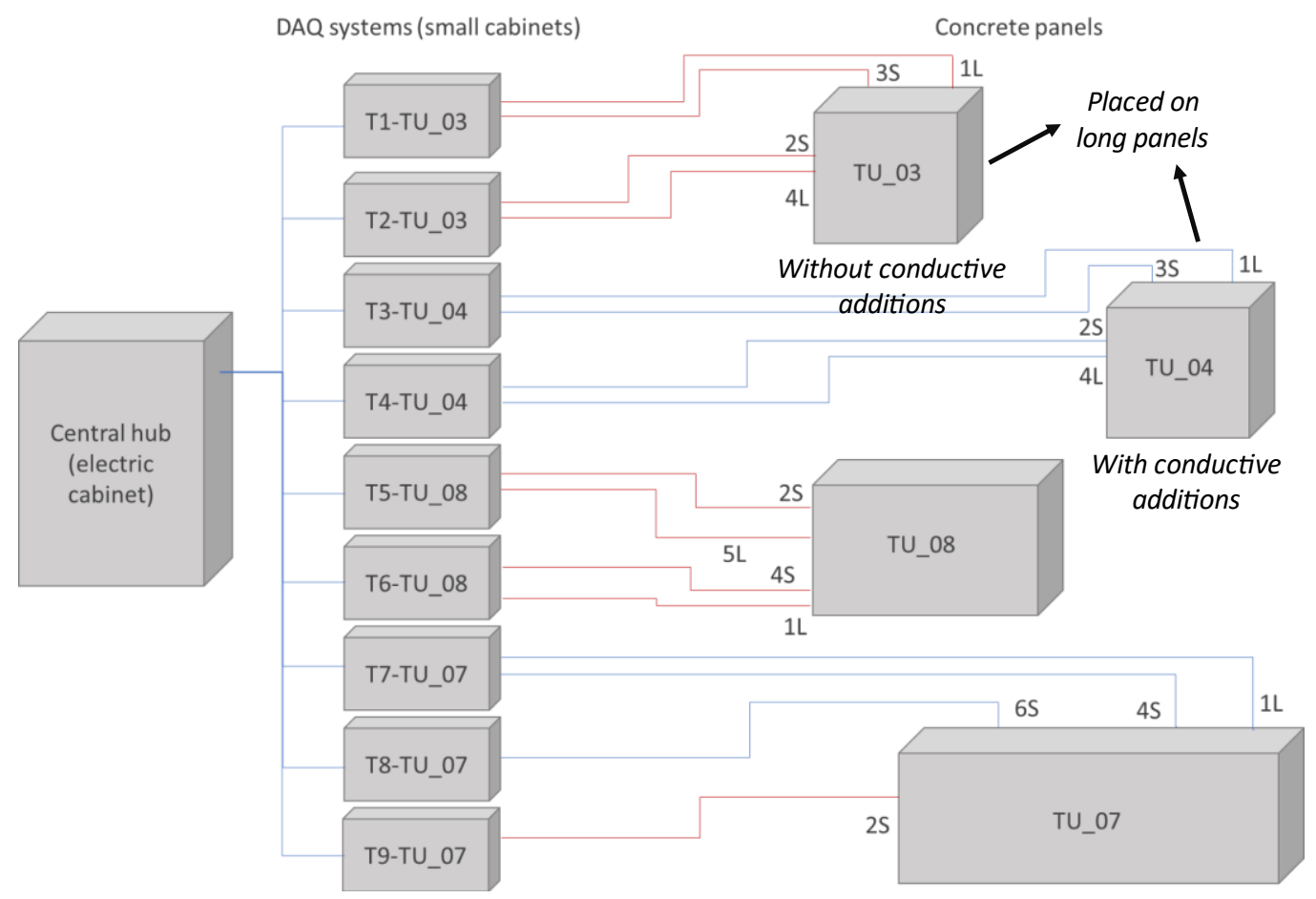

Figure 7. Monitoring system at the demo site in León (Spain).
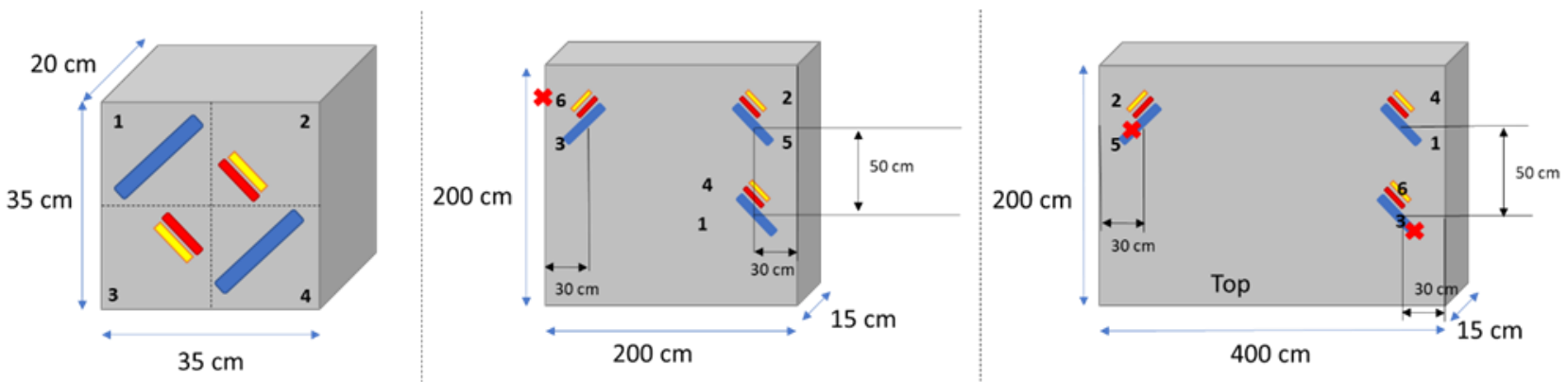

Figure 8. Concrete panels exposed to the demo site in León (Spain): no. 2 panels of $35 \times 35 \times 20 \mathrm{~cm}^{3}$ (left), no. 1 panel of $200 \times 200 \times 15 \mathrm{~cm} 3$ (centre) and no. 1 panel of $200 \times 400 \times 15 \mathrm{~cm}^{3}$ (right). Legend: 4-electrode arrays with 4-cm spacing are reported in blue, 4-electrode arrays with 1-cm spacing are reported in red, temperature sensors are reported in yellow.

pick out the monitoring period to be shown (Figure 5). It is possible to save data, send them to the email address inserted in the registration phase (with the options to save the data related to all the panels exposed in the demo site), as well as to make a graph with the selected options (Figure 6).

\subsection{The concrete panels monitored in the project demo sites}

The concrete panels exposed in the demo sites of the EnDurCrete project were manufactured with low-clinker cement (aimed at reducing the carbon footprint, given that the production of ordinary Portland cement - OPC - is responsible for approximately $8 \%$ of global $\mathrm{CO}_{2}$ emissions [32]), developed within the same project [33]. Two different mix designs were formulated, with and without conductive additions.

The monitoring system developed was tested in a Spanish demo site, representative of a harsh setting: a tunnel in León, which is an underground environment rich in sulphates. In particular, 2 small panels of $35 \times 35 \times 20 \mathrm{~cm}^{3}$ (with and without conductive additions), 1 long panel of $200 \times 200 \times 15 \mathrm{~cm}^{3}$ and another long panel of $200 \times 400 \times 15 \mathrm{~cm}^{3}$ were exposed (Figure 7).
In each small panel 4-electrode arrays were embedded, whereas 6 ones in longer panels, in order to have a proper distributed sensor network (Figure 8). Arrays with different electrode spacings were used, to be installed at depths respecting the literature recommendation (a minimum distance of twice the contact spacing from the element edge should be guaranteed):

- 4-cm spacing, installed at a depth of $16 \mathrm{~cm}$ and $10 \mathrm{~cm}$ in small and long panels, respectively;

- $\quad 1-\mathrm{cm}$ spacing, to be installed at a depth of $4 \mathrm{~cm}$ and $5 \mathrm{~cm}$ in small and long panels, respectively.

The monitoring system configuration is reported in Figure 7 , whereas the electrodes configuration in Figure 8. It is worthy to mention that temperature sensors were embedded in the monitored concrete specimens, whereas the moisture content was not assessed; indeed, it is out of the scope of the proposed monitoring system to distinguish among the different factors contributing to the results, since the main aim is to identify ingress of contaminants that can possibly threaten the concrete durability. The positioning of the concrete panels in the tunnel is shown in Figure 9. 


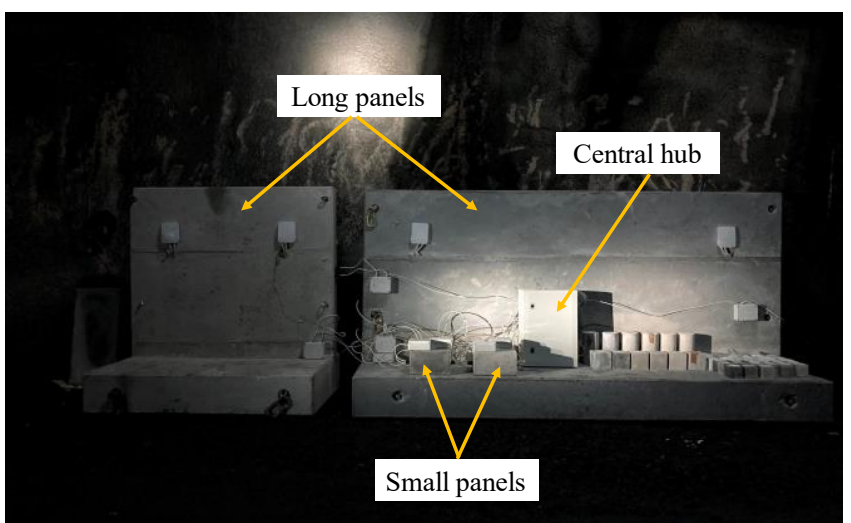

Figure 9. Positioning of concrete panels in the tunnel at the demo site of León (Spain); concrete panels with embedded sensors for the measurement of electrical impedance are 4 ( 2 small and 2 long).

\section{RESULTS AND DISCUSSION}

\subsection{Laboratory tests}

The results concerning the validation of the measurement system are reported for the real part of electrical impedance measured at $10 \mathrm{kHz}$ in Figure 10 (single measurements are compared on each day of the time interval considered after the initial concrete curing period); measurements were performed until 15 days after casting.

It is possible to notice that the measurement node developed provides results compatible to those obtained from the gold standard, with absolute percentage errors lower than $10 \%$. The advantages of the developed node are multiple:

- Compactness, thus possibility to be installed close to the element to be monitored: this allows to minimize the cables length and consequently to reduce their influence on the measurement results, as well as to minimize parasitic electrical components;

- Reduced cost, approximately 3\% of the reference equipment;

- Modularity of the system, which results particularly useful for the development of a distributed sensor network, which can be also modified at a later time.

A comparison was made also concerning the electrodes spacing (Figure 11). As expected, the real part of electrical impedance is higher with the shorter electrode spacing, since the sensing volume is smaller, resulting in higher opposition to the electric current flow. However, both the measurements show a trend increasing with curing time, as expected from the literature [16], because of the continuous hydration of the cement paste

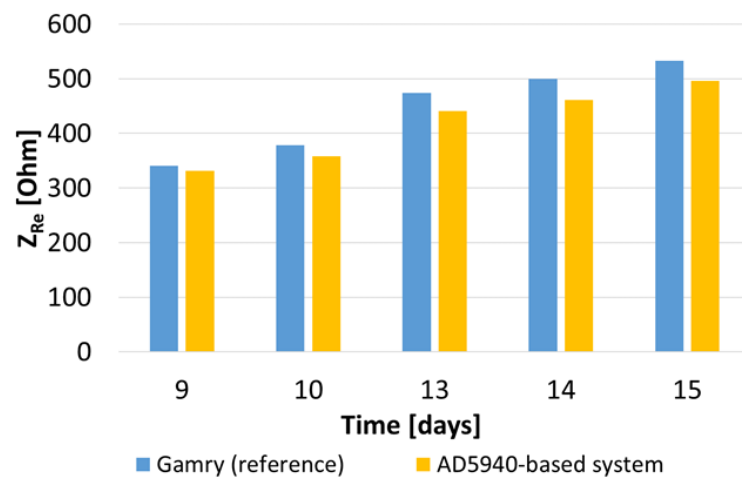

Figure 10. Comparison between measurement results obtained with the system exploiting AD5940 chip (yellow data) and reference equipment (Gamry Reference 600, blue data) - measurement frequency: $10 \mathrm{kHz}$.

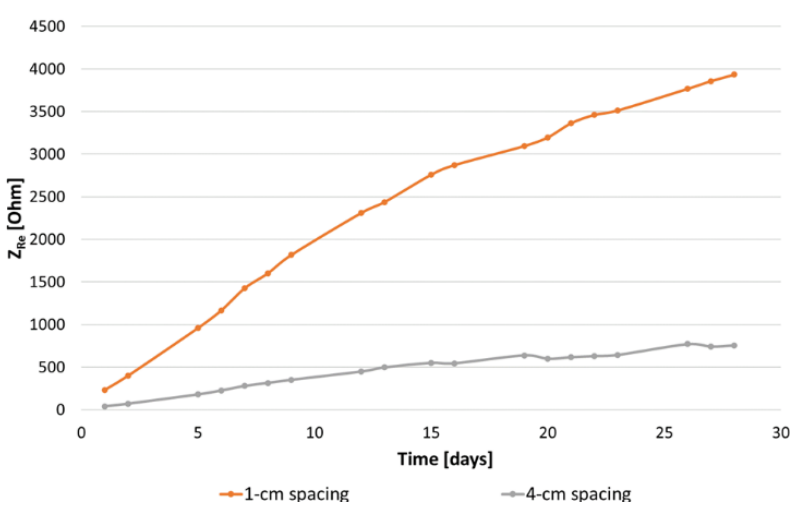

Figure 11. Comparison between results obtained by electrode arrays with different spacings: $1 \mathrm{~cm}$ (orange data) and $4 \mathrm{~cm}$ (grey data) - measurement frequency: $10 \mathrm{kHz}$.

and the gradual water evaporation. In this way, it is possible to monitor different sensing volumes within the same element, also considering surfaces looking out different exposure conditions.

Some data pre-processing capabilities were also embedded in the system, namely a moving median filter (sliding window: 9 samples) combined to a wavelet decomposition (Discrete Meyer wavelet of level 5). Data were also normalised with respect to the initial value, in order to observe the variations over time, independently from the absolute values (less significant for monitoring purposes, looking for variations due to particular events, such as cracks or contaminants penetration).

\subsection{Results from tunnel demo site}

Some examples of the results related to the data acquired from 8th October 2020 to 28th June 2021 (approximately 9 months) are reported in this paragraph. In particular, three sensors are considered: 2-electrode arrays with 1-cm spacing embedded in two small panels with (Figure 12) and without (Figure 13) conductive additions, one electrode array with 4-cm spacing embedded in a long panel without conductive additions (Figure 14). It can be observed that the monitoring system did not show any faults during the demo test activities and data were not affected by any issues attributable to the aggressive conditions of the exposure environment since there are no anomalous spikes or particular increase/decrease due to external phenomena. As expected, the electrical impedance module increases with decreasing temperature; however, it is worthy to note that

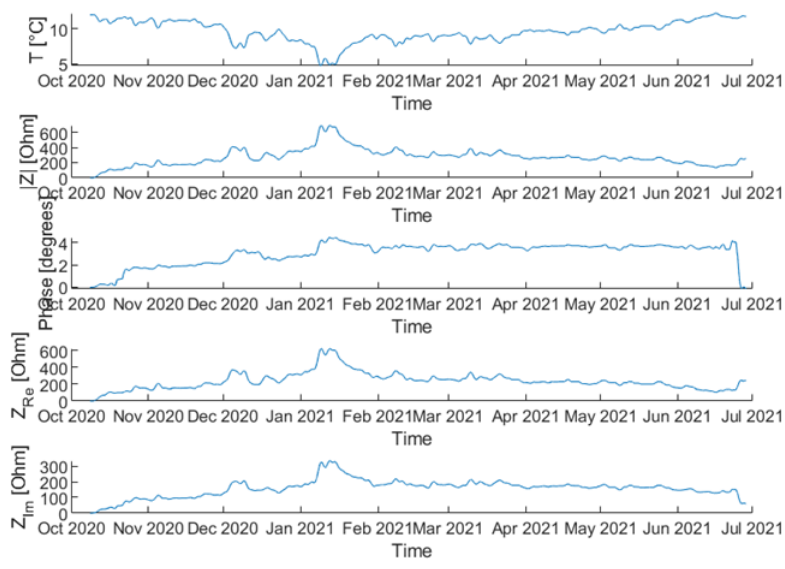

Figure 12. Results related to a small panel with conductive additions (1-cm spacing electrode array): temperature, electrical impedance module, electrical impedance phase, real and imaginary parts of electrical impedance (from top to bottom) - measurement frequency: $10 \mathrm{kHz}$. 


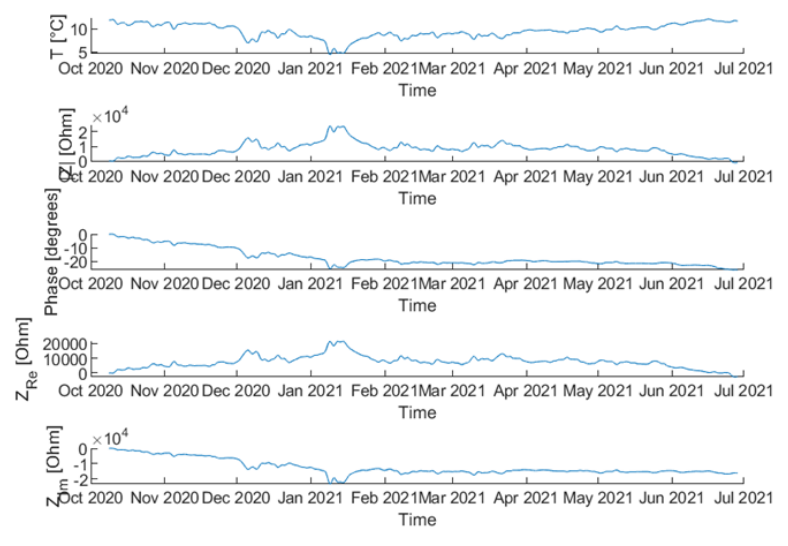

Figure 13. Results related to a small panel without conductive additions (1$\mathrm{cm}$ spacing electrode array): temperature, electrical impedance module, electrical impedance phase, real and imaginary parts of electrical impedance (from top to bottom) - measurement frequency: $10 \mathrm{kHz}$

underground environment makes temperature values quite stable and this reflects on the electrical impedance trend (no day-night cycles can be identified, neither in temperature nor in electrical impedance signals). In addition, environmental sensors were employed in the demo site to continuously monitor environmental temperature and relative humidity, which resulted both quite stable in the considered monitoring time interval $(T=$ $10{ }^{\circ} \mathrm{C}-15{ }^{\circ} \mathrm{C}$ and $\mathrm{RH}=70 \%-80 \%$, respectively). In line with what obtained in laboratory tests, the electrical impedance is generally higher when electrode spacing is shorter (see Figure 13 with respect to Figure 14), since the electrical current flows in the sensing volume less easily, probably due to the fact that considering a minor material volume enhances the effects of particularly non-conductive elements (e.g. aggregates). Moreover, it is confirmed that conductive additions lower the electrical impedance of concrete panels (see Figure 12 in comparison to Figure 13), hence allowing a monitoring through the use of relatively low-cost instrumentation, with limited metrological performance.

The small panels (Figure 12 and Figure 13) show a positive phase before normalization of the signal (with respect to the initial value); this results in an inductive imaginary part, contrary to what it is expected from the literature [34]. This is probably due to a capacitive coupling with ground, as it happened during laboratory tests; in fact, this do not happen in long panels (Figure

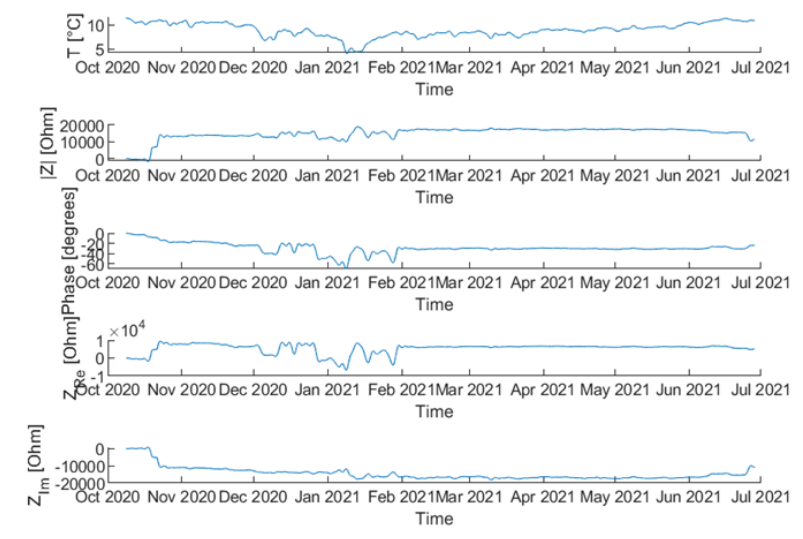

Figure 14. Results related to a long panel without conductive additions (4-cm spacing electrode array): temperature, electrical impedance module, electrical impedance phase, real and imaginary parts of electrical impedance (from top to bottom) - measurement frequency: $10 \mathrm{kHz}$.
14), which are leaning directly on the ground (Figure 9). However, this does not impede the monitoring of those elements and the identification of eventual factors hindering durability.

The monitoring phase will continue at least until the project end (December 2021), in order to evaluate possible uncertainty sources linked to the ingress of aggressive substances (e.g. sulphates), which could hinder the concrete elements durability.

\section{CONCLUSIONS}

The ongoing validation phase of the developed monitoring system at the Spanish demo site of León is providing interesting results, even though the small variations recorded so far do not highlight any particular event associated to the ingress of contaminants. The measurement system presented in the paper is continuously generating data from the field application, no matter the aggressive exposure conditions. It is worthy to underline the importance of properly choosing the locations of sensors, being a local measurement with a defined sensing volume; the use of conductive additions allows to employ lowcost modular equipment, with the possibility to realize a distribute sensor network with sensing nodes in correspondence of those areas more prone to damages or contaminants ingress, which could impact on the structure durability and efficiency during the whole life cycle.

In the future, the monitoring system will be exploited also in different harsh environments, such as a typical marine site which is rich in chlorides.

\section{ACKNOWLEDGEMENT}

This research activity was carried out within the EnDurCrete (New Environmental friendly and Durable conCrete, integrating industrial by-products and hybrid systems, for civil, industrial, and offshore applications) project, funded by the European Union's Horizon 2020 research and innovation programme under grant agreement $\mathrm{n}^{\circ} 760639$. Authors would like to thank ACCIONA group for having prepared concrete specimens to be tested, NTS and SIKA for having provided aggregates and admixtures, respectively.

\section{REFERENCES}

[1] M. P. Limongelli, SHM for informed management of civil structures and infrastructure, J. Civ. Struct. Heal. Monit 10 (2020) pp. 739-741.

DOI: $\underline{10.1007 / s 13349-020-00439-8}$

[2] F. Lamonaca, C. Scuro, P. F. Sciammarella, R. S. Olivito, D. Grimaldi, D. L. Carnì, A layered IoT-based architecture for a distributed structural health monitoring system system, Acta IMEKO. 8 (2019) 2, pp. 45-52. DOI: $10.21014 /$ ACTA IMEKO.V8I2.640

[3] A. H. Alavi, P. Jiao, W. G. Buttlar, N. Lajnef, Internet of Thingsenabled smart cities: State-of-the-art and future trends, Measurement 129 (2018) pp. 589-606.

DOI: $10.1016 / J . M E A S U R E M E N T .2018 .07 .067$

[4] F. Zonzini, C. Aguzzi, L. Gigli, L. Sciullo, N. Testoni, L. De Marchi, M. Di Felice, T. S. Cinotti, C. Mennuti, A. Marzani, Structural health monitoring and prognostic of industrial plants and civil structures: A Sensor to cloud architecture, IEEE Instrum. Meas. Mag. 23 (2020) pp. 21-27. DOI: $\underline{10.1109 / \text { MIM.2020.9289069 }}$

[5] The Portland Cement Association, America's Cement Manufaxcturers - Durability of concrete, (n.d.). Online [Accessed 05 December 2021].

https://www.cement.org/learn/concrete-technology/durability 
[6] G. Cosoli, A. Mobili, N. Giulietti, P. Chiariotti, G. Pandarese, F. Tittarelli, T. Bellezze, N. Mikanovic, G. M. Revel, Performance of concretes manufactured with newly developed low-clinker cements exposed to water and chlorides: Characterization by means of electrical impedance measurements, Constr. Build. Mater. 271 (2020) 121546

DOI: $10.1016 /$ i.conbuildmat.2020.121546

[7] W. R. de Sitter, Costs of service life optimization "The law of fives", CEB-RILEM Workshop on Durability of Concrete Structures, Copenhagen, Denmark, 18-20 May 1983. In CEB Bulletin d'Information, vol. 152, Comité Euro-International du Béton, (1984) pp. 131-134.

[8] N. Epple, D. F. Barroso, E. Niederleithinger, Towards monitoring of concrete structures with embedded ultrasound sensors and Coda waves - First results of DFG for CoDA, in: Lect. Notes Civ. Eng., Springer Science and Business Media Deutschland GmbH, (2021) pp. 266-275.

DOI: $10.1007 / 978-3-030-64594-627$

[9] M. Goueygou, O. Abraham, J. F. Lataste, A comparative study of two non-destructive testing methods to assess near-surface mechanical damage in concrete structures, NDT E Int. 41(6) (2008) pp. 448-456. DOI: $10.1016 /$ i.ndteint.2008.03.001

[10] C. Z. Dong, F. N. Catbas, A review of computer vision-based structural health monitoring at local and global levels, Struct. Heal. Monit. 20 (2021) pp. 692-743. DOI: $10.1177 / 1475921720935585$

[11] D. Feng, M. Q. Feng, Computer vision for SHM of civil infrastructure: From dynamic response measurement to damage detection - A review, Eng. Struct. 156 (2018) pp. 105-117. DOI: $10.1016 /$ i.engstruct.2017.11.018

[12] S. Pozzer, F. Dalla Rosa, Z.M.C. Pravia, E. Rezazadeh Azar, X. Maldague, Long-term numerical analysis of subsurface delamination detection in concrete slabs via infrared thermography, Appl. Sci. 11(10) (2021), art. no. 4323. DOI: $10.3390 /$ app 11104323

[13] P. Cotič, D. Kolarič, V. B. Bosiljkov, V. Bosiljkov, Z. Jagličić, Determination of the applicability and limits of void and delamination detection in concrete structures using infrared thermography, NDT E Int. 74 (2015) pp. 87-93. DOI: $10.1016 /$ j.ndteint.2015.05.003

[14] K. Tešić, A. Baričević, M. Serdar, Non-destructive corrosion inspection of reinforced concrete using ground-penetrating radar: A review, Materials 14(4) (2021), art. no. 975. DOI: $\underline{10.3390 / \mathrm{ma1} 14040975}$

[15] X. Dérobert, G. Villain, Effect of water and chloride contents and carbonation on the electromagnetic characterization of concretes on the GPR frequency band through designs of experiment, NDT E Int. 92 (2017) pp. 187-198.

DOI: $10.1016 /$ i.ndteint.2017.09.001

[16] A. Belli, A. Mobili, T. Bellezze, F. Tittarelli, P. Cachim, Evaluating the self-sensing ability of cement mortars manufactured with graphene nanoplatelets, virgin or recycled carbon fibers through piezoresistivity tests, Sustainability 10(11) (2018), art. no. 4013. DOI: $10.3390 /$ su10114013

[17] B. A. de Castro, F. G. Baptista, F. Ciampa, New signal processing approach for structural health monitoring in noisy environments based on impedance measurements, Measurement 137 (2019) pp. $155-167$. DOI: 10.1016/J.MEASUREMENT.2019.01.054

[18] M. Saleem, M. Shameem, S. E. Hussain, M. Maslehuddin, Effect of moisture, chloride and sulphate contamination on the electrical resistivity of Portland cement concrete, Constr. Build. Mater. 10(3) (1996), pp. 209-214.

DOI: $10.1016 / 0950-0618(95) 00078-\mathrm{X}$

[19] I.-S. Yoon, C.-H. Chang, Effect of Chloride on Electrical resistivity in carbonated and non-carbonated concrete, Appl. Sci. 10(18) (2020), art. no. 6272 .

DOI: $10.3390 /$ app 10186272
[20] P. Azarsa, R. Gupta, Electrical resistivity of concrete for durability evaluation: A review, 2017 (2017), art. no. 8453095. DOI: $10.1155 / 2017 / 8453095$

[21] K. R. Gowers, S. G. Millard, Measurement of concrete resistivity for assessment of corrosion severity of steel using Wenner technique, Mater. J. 96 (1999) pp. 536-541. DOI: $10.14359 / 655$

[22] G. Cosoli, A. Mobili, F. Tittarelli, G. M. Revel, P. Chiariotti, Electrical resistivity and electrical impedance measurement in mortar and concrete elements: A systematic review, Appl. Sci. 10 (24) (2020), art. no. 9152. DOI: $10.3390 / \operatorname{app} 10249152$

[23] F. Wenner, A method for measuring Earth resistivity, J. Washingt. Acad. Sci. 5 (1915) pp. 561-563. Online [Accessed 05 December 2021] https://nvlpubs.nist.gov/nistpubs/bulletin/12/nbsbulletinv12n4 p469 A2b.pdf

[24] T.-C. Hou, Wireless and electromechanical Approaches for strain sensing and crack detection in fiber reinforced cementitious materials, University of Michigan, Ph.D. Thesis, 2008. Online [Accessed 05 December 2021]

https://deepblue.lib.umich.edu/bitstream/handle/2027.42/6160 6/tschou 1.pdf? sequence $=1$ \&is Allowed $={ }_{\mathrm{V}}$

[25] T. Wandowski, P. H. Malinowski, W. M. Ostachowicz, Improving the EMI-based damage detection in composites by calibration of AD5933 chip, Measurement. 171 (2021) art. no. 108806. DOI: 10.1016/J.MEASUREMENT.2020.108806

[26] A. A. Ramezanianpour, A. Pilvar, M. Mahdikhani, F. Moodi, Practical evaluation of relationship between concrete resistivity, water penetration, rapid chloride penetration and compressive strength, Constr. Build. Mater. 25(5) (2011) pp. 2472-2479. DOI: $10.1016 /$ i.conbuildmat.2010.11.069

[27] X. Dérobert, J. F. Lataste, J. P. Balayssac, S. Laurens, Evaluation of chloride contamination in concrete using electromagnetic nondestructive testing methods, NDT E Int. 89 (2017) 19-29. DOI: $10.1016 /$ i.ndteint.2017.03.006

[28] J. Zhang, Z. Li, Hydration process of cements with superplasticizer monitored by non-contact resistivity measurement, Proc. Adv. Test. Fresh Cem. Mater. Ed. by H. W. Reinhardt, Aug. 3-4, 2006, Stuttgart, Ger. (2006).

[29] J.F. Lataste, C. Sirieix, D. Breysse, M. Frappa, Electrical resistivity measurement applied to cracking assessment on reinforced concrete structures in civil engineering, NDT E Int. 36(6) (2003) pp. 383-394. DOI: $10.1016 /$ S0963-8695(03)00013-6

[30] N. Wiwattanachang, P. H. Giao, Monitoring crack development in fiber concrete beam by using electrical resistivity imaging, J. Appl. Geophys. 75(2) (2011) pp. 294-304. DOI: 10.1016/i.jappgeo.2011.06.009

[31] C. G. Berrocal, K. Hornbostel, M. R. Geiker, I. Löfgren, K. Lundgren, D. G. Bekas, Electrical resistivity measurements in steel fibre reinforced cementitious materials, Cem. Concr. Compos. 89 (2018) pp. 216-229. DOI: $10.1016 /$ i.cemconcomp.2018.03.015

[32] R. M. Andrew, Global $\mathrm{CO}_{2}$ emissions from cement production, Earth Syst. Sci. Data. 10 (2018), pp. 195-217. DOI: $10.5194 /$ essd-10-195-2018

[33] G. Bolte, M. Zajac, J. Skocek, M. Ben Haha, Development of composite cements characterized by low environmental footprint, J. Clean. Prod. 226 (2019) pp. 503-514. DOI: $10.1016 /$ j.jclepro.2019.04.050

[34] J. Torrents Dolz, P. Juan Garcia, A. Aguado de Cea, Electrical impedance as a technique for civil engineer structures surveillance: considerations on the galvanic insulation of samples. Online [Accessed 05 December 2021]. https://upcommons.upc.edu/bitstream/handle/2117/2865/agu ado measurement 1.pdf 